Arab World English Journal (AWEJ) 2nd Special Issue on Covid 19 Challenges January 2022

DOI: https://dx.doi.org/10.24093/awej/covid2.24

\title{
The King Abdulaziz University COVID-19 e-vaccine: An Evaluation of the Emergency Training Knowledge Model
}

\author{
Hisham Jameel Bardesi \\ Deanship of e- Learning and Distance Education \\ King Abdulaziz University \\ Jeddah, Saudi Arabia \\ Ibrahim Garba \\ Faculty of Applied Studies \\ King Abdulaziz University \\ Jeddah, Saudi Arabia \\ Corresponding Author: igarba90@gmail.com
}

Received:12/12/2021

Accepted:1/11/2022

Published: $1 / 24 / 2022$

\section{Abstract}

King Abdulaziz University (KAU) took extra measures in response to COVID-19 in March 2020. The current research evaluated an Emergency Training Session (ETS) Knowledge Model during the pandemic with the aim of identifying for the Deanship of e-Learning and Distance Education (DeLDE) to evaluate how the e-learning services support learning and teaching at KAU beyond the pandemic. The Knowledge Model gathered quantitative data regarding the learning management system (LMS) e-service usage from students ( $n=2359$ female and $n=1580$ male) and teachers $(n=414)$. Also, the model used insights from qualitative data that came from the critical reflections of the trainer-researcher. We offer critical insight from the review of the literature and the results of the evaluation. First, the evaluation outlines the importance of evaluators bringing some assumptions with them when evaluating programmes. In the case of DeLDE, the assumptions promoted the interest of DeLDE in generating knowledge from different perspectives regarding DeLDE's e-learning services contextualised as the ETS Knowledge Model. The assumptions gave importance to behaviourist and constructivist learning theories and a goal and decision-making philosophy of evaluation. Finally, contextualising the participant-researchers as the Dean and trainer at DeLDE, the evaluation gained from the participants' familiarity of the ETS Knowledge Model's context.

Keywords: COVID-19, critical reflection, e-learning policy, emergency training evaluation, higher education, knowledge-evaluation, process analysis, Saudi university context, strategic planning, sustainable development

Cite as: Bardesi, H. J., \& Garba, I. (2022). The King Abdulaziz University COVID-19 evaccine: An Evaluation of the Emergency Training Knowledge Model. Arab World English Journal (AWEJ) $2^{\text {nd }}$ Special Issue on Covid 19 Challenges (2) 356-376.

DOI: https://dx.doi.org/10.24093/awej/covid2.24 
Introduction

COVID-19 had a global impact on higher education, educators, and institutions (UNESCO, 2020). No sooner had the Saudi Arabian Ministries of Health, Education, and the KAU Presidency announced the cessation of education from the main campus than learning and teaching returned to a virtual environment. In the background, the Deanship of e-Learning and Distance Education (DeLDE) supported KAU teachers' transition to teaching online. DeLDE predicted the announcement through a series of initiatives. The initiatives emerged with the sole purpose of activating measures that equipped KAU teachers with the e-Learning resources to sustain learning and teaching online for the remainder of the 2019 second semester. Accordingly, the activities indicated the need to evaluate e-learning measures (Cameron \& Whetten, 1983).

\section{The DeLDE activities}

DeLDE carried out a series of activities culminating in ETS to support KAU teachers between February 2020 and June 2020. The ETS included training KAU teachers to use eLearning tools on the learning management system (LMS) adopted in most Saudi Universities Blackboard $^{\mathrm{TM}}$ (Almaiah \& Alyoussef, 2019). At the pandemic's start, DeLDE activated the process that gave rise to the ETS (Figure 1). The support included training at colleges, in-house at DeLDE, online, and the use of social media to provide KAU members with crucial information. To provide the training at the colleges, DeLDE trainers visited schools such as Medicine, Dentistry, Pharmacy, and the Applied Medical Sciences. To train in-house, teachers walked in and utilised the training centres available at DeLDE. Training online began before the cessation of learning and teaching on campus. So, the training online used the LMS, especially after remote learning and teaching became mandatory. Finally, the use of DeLDE's official Twitter account (\#kau_e-learning) and emails saw that crucial information circulated to all relevant stakeholders during the remote learning and teaching period that started in March 2020.

Training at colleges

Training in-house at DeLDE

Training online

Social Media support

Figure 1. Emergency Training Sessions

Note. The different training sessions are offered during the ETS.

\section{Grounding effectiveness to issues}

Cameron and Whetten (1983) contextualised that the pandemic represented derailment for units like DeLDE and the wider higher education institutions. Before the pandemic meeting, the operational goals for DeLDE did not require engaging with emergency measures. However, to measure its effectiveness, new knowledge about the consequences of the derailment were in order. The knowledge necessary to measure the effectiveness of the activities requires some theoretical and empirical grounding (Barnes, 2020; Cameron \& Whetten, 1983; Ilhan, 2020; Marshall, 2018; Venkatraman \& Ramanujam, 1986). Cameron and Whetten (1983) identify steps towards evaluating education's sustainment using e-learning resources beyond the March 2020 crisis. For instance, the importance of knowing about the use of e-learning in a published medium provides credibility in evidencing the efforts of DeLDE. The literature review section identifies the importance of a philosophical view of evaluation. Also, in keeping with working 
within a highly fluid environment, the knowledge generates from evaluating the e-learning usage during the pandemic may contribute towards understanding how KAU sustains education during the pandemic.

\section{Literature review}

DeLDE requires an understanding of knowledge generated from the use of the ETS Knowledge Model for two reasons. First, the knowledge is needed for DeLDE to assess the use of e-learning during the pandemic. So, the type of knowledge from the evaluations guides the literature review. Second, DeLDE needs to understand the implications of assessing the knowledge. Therefore, in the current study, the literature review works on two fronts, first to understand how to evaluate programs and use the implications of evaluations (Weick, 1976). The critical review below outlines the importance of evaluators to bring some assumptions with them when evaluating programmes. The assumptions include DeLDE maintaining a valuable interest in evaluating e-learning services contextualised as the ETS Knowledge Model. Kirkpatrick (1998) offers evaluators four levels of analysis using quantitative and qualitative data for the evaluation (Alsalamah \& Callinan, 2021; Asgar \& Satyanarayana, 2021; Patel et al., 2018; Siengthai, 2015; Sim \& Radloff, 2008). The context is also essential for evaluating the ETS Knowledge Model, which challenges the Kirkpatrick model. Brinkerhoff (2005) outlines the Case success model, which does not restrict the context. So, the current evaluation identifies prior knowledge such as critical thinking (Burke \& Hutchins, 2007), critical reflection (1990), and learning theories like behaviourism and constructivism Hean et al. (2009). Finally, evaluating the ETS Knowledge Model may include a philosophical view when evaluating the outcome (Easterby-Smith, 1994) of the ETS Knowledge Model using quantitative data. Another view included a transactional one (Gustafsson et al., 2014), which emphasised the evaluator's and DeLDE perspectives when evaluating the ETS Knowledge Model (Gustafsson et al., 2014; House, 1980; Stake, 2005). The Dean and trainer from DeLDE represent the participantresearchers familiar with the ETS Knowledge Model during the pandemic.

\section{The Kirkpatrick model}

The Kirkpatrick model provides a quick and innovative approach to gather data to evaluate the outcome of using DeLDE e-learning services (Reio et al., 2017). The Kirkpatrick model provided results of the outcome of a programme (Alsalamah \& Callinan, 2021). So, the Kirkpatrick model aims to give evaluators results to understand how the programme users reacted to using the programme. The results may be gathered using quantitative data taken from surveys. In the DeLDE context, a survey provides knowledge from KAU participants about elearning services.

Kirkpatrick (1998) offers four levels (Figure 2) that DeLDE may use to evaluate the use of e-learning services during the pandemic. Level 1 uses a questionnaire to gather numeric data from students and participants about their reactions to e-learning services. The items in the questionnaire include a Likert scale that asks participants to select their agreement about their knowledge, skills, and attitudes (Alsalamah \& Callinan, 2021). Accordingly, the Kirkpatrick model provides access to Level 1 data to measure the KAU students' satisfaction with the elearning services for learning purposes. The Level 2 data measures teachers' agreement with using e-learning services and ETS training. Level 3 may offer access to reflective data about 
Arab World English Journal (AWEJ) 2nd Special Issue on Covid 19 Challenges January 2022

The King Abdulaziz University COVID-19 e-vaccine: An Evaluation

Bardesi \& Garba

learning and teaching. Finally, Level 4 provides access to data about the value of the e-Learning services for DeLDE.

\begin{tabular}{|l|l|}
\hline \multicolumn{1}{|c|}{ Levels } & \multicolumn{1}{c|}{ Description } \\
\hline 1 Reaction & Satisfaction with e-Learning resources (course, content, instructor, LMS) \\
\hline 2 Learning & Acquistion of knowledge and skills, change in attitude due to e-Learning training. \\
\hline 3 Behaviour & Improvement in teaching and learning due to Level 1 and Level 2 changes \\
\hline 4 Results & Evaluating results in relation to DeLDE e-Learning goals \\
\hline
\end{tabular}

Figure 2. The Kirkpatrick Evaluation Model levels and descriptions

Note. The levels described in the Kirkpatrick Model taken from Kirkpatrick (1998) Kirkpatrick in practice

Researchers have used the Kirkpatrick model to evaluate the outcome of programmes. Alsalamah and Callinan (2021) required knowledge of the outcome of training headteachers at a Saudi based programme. Alsalamah and Callinan (2021) used surveys and interviews to gather quantitative and qualitative data from 250 female teachers. Then, the results were evaluated using Kirpatrick (2009). The evaluation concluded that the Ministry of Education sponsored programme effectively impacted the knowledge and skills headteachers acquired to take on public leadership roles. Other researchers have used the approach taken by Alsalamah and Callinan to evaluate training (Asgar \& Satyanarayana, 2021; Patel et al., 2018) from different domains (Asgar \& Satyanarayana, 2021; Siengthai, 2015; Sim \& Radloff, 2008). The Kirkpatrick model is influential in evaluating programmes at higher education institutions.

\section{Challenging Kirkpatrick}

Other views of evaluating programmes challenge the Kirkpatrick model. Easterby-Smith (1994) argued that the context of the ETS provided critical information for DeLDE. The context surfaced the ideas about the purpose of setting up the ETS and what happens during the ETS. Hence, evaluating the ETS Knowledge Model need not ignore the context for DeLDE. Brinkerhoff (2005) argued that a programme did not provide a magic stick effect on the wider performance of the organisation. For instance, when offering the e-learning services at DeLDE, the services offered to students and teachers did not improve the learning and teaching from evaluating the e-learning services. Instead, evaluating the contexts raises how well the e-learning services at KAU sustained learning and teaching in the long term, which challenges the Kirkpatrick model.

\section{The case success model}

Lee et al. (2017) required knowledge about training employees new on a government programme in Korea. The researchers used a case success method to gather data on how the employees transferred the skills they acquired from the 1,048-hour programme. Lee et al. (2017) evaluated their results using Brinkerhoff (2005). They cited Burke and Hutchins (2007) to conclude the active thinking of participants to encourage the transfer of skills from the programme to the government jobs. The conclusions from using the case success method agreed 
Arab World English Journal (AWEJ) 2nd Special Issue on Covid 19 Challenges January 2022

The King Abdulaziz University COVID-19 e-vaccine: An Evaluation

Bardesi \& Garba

with the influence of reflection to transform learning (Hean et al., 2009; McIntosh et al., 2018; Mezirow, 1990; Mulcahy, 2020; Osam \& Nold, 2020; Siengthai, 2015).

\section{The need for prior knowledge}

Mulcahy (2020) used Brinkerhoff to focus on prior knowledge that could guide evaluating programmes. Prior knowledge from the participants involved with the programme provided valuable information. Siengthai (2015) reflected on training improvements that used the Kirkpatrick model to evaluate the public sector training in Thailand. Also, Siengthai reiterated what can go into training, called the inputs and the process for training. Though Siengthai did not elaborate on the method of reflection used, the suggestion opens the door for evaluating practice. Also, Brinkerhoff (2005) and Mulcahy (2020) did not specify the concept related to prior knowledge. The different views indicated that evaluation might focus on the programme's outcome and consider the implication using knowledge known about the programme referred to as knowledge. Mulcahy (2020) generally defined prior knowledge, which we turn to next.

\section{Behavioural and constructivist priors}

Hean et al. (2009) underpinned evaluation around learning theories. Learning theories widen the perspectives for evaluating programmes. For example, according to Hean et al. (2009), using Kirkpatrick put a behaviourist perspective into the evaluation. A behaviourist perspective interpreted the students and teachers' behaviour as their satisfaction with the e-learning services during the pandemic. Also, using critical reflection put a constructivist perspective into the evaluation. Hean et al. (2009) cited Mezirow (1990), who widens the concept of prior knowledge using critical reflection. Galloway (2005) critiqued the Kirkpatrick model due to the inability of the Kirkpatrick model to capture reflection at Levels 1 and 2 of the model. Hence, it was essential to gather the reflection from students and teachers, which restricted the Kirkpatrick model. Also, it was essential to consider the context of using the e-learning services because the responses at Level 1 and Level 2 of the Kirkpatrick model measured student and teacher perceptions using a survey. In a Kirkpatrick model, rather than the reflections from students and teachers, the critical reflection from the trainer-researcher was contextualised at Level 3 of the Kirkpatrick model. One reason was that during and after the training, there were no considerations to gather feedback from the trainees. The situation was dire and had a different goal. So, none of the trainees was contacted after the training to gather their critical reflections.

Hence, the analytical component that influenced the evaluation came from the perspective of learning theories. Critical reflection catapults the insight of the trainer-researcher into the evaluation (Rosellini, 2019). Thus, the use of a learning theory identifies constructivism as the perspective that justifies critical reflection. Constructivism contrasts with behaviourism as a learning theory. A behaviourist perspective gives the outcome of the e-learning services significance, while the constructivist perspective gives the process meaning (Brinkerhoff, 2005; Hean et al., 2009). The learning theories raise the use of the perspectives as a standard to measure the value of the ETS Knowledge Model for DeLDE (Lincoln \& Guba,1994).

\section{The DeLDE priors}

The evaluation of programmes represented a challenge for higher education institutions (HEI) (Rosellini, 2019). Undoubtedly, the current evaluation faced a similar challenge. Lebeau and Alruwaili (2021) contextualised the latitude of Saudi HEIs, which reduced the challenge of 
seeking data. The meaning of the latitude for DeLDE was the easing of the regulations for research whereby KAU gives the researcher ethical approval to plan and conduct research. DeLDE needed to evaluate the ETS Knowledge Model rather than gather data from participants to inform the evaluation. The evaluation of the model differs from the domain that Alsalamah and Callinan (2021), Lee et al. (2017), and Mulcahy (2020) engaged within their research. DeLDE needed more than knowledge about the participants at the end of their training. It was essential to transfer any learning from the evaluation to improve the e-learning services.

\section{A transactional philosophical view of evaluation}

Cameron and Whetten (1983) identified the perspective of DeLDE to play a part in the evaluation process. Evaluating the decisions that supported the use of the e-learning services at KAU contextualised the DeLDE perspective. The perspective ensured that the value of the evaluation benefited DeLDE to improve its e-learning services. Ballantine et al. (2000) recommended a philosophical basis when designing evaluations. The subject of the evaluation was the decision-making process. So, the philosophical basis was established around the evaluation of the decision process. Easterby-Smith (1994) provided a taxonomy for conducting evaluations. One evaluation included measuring the outcome of programmes. Such evaluations were similar to the research that used the Kirkpatrick models. The similarity is tied to observing participants' behaviour, such as their responses to items from a survey questionnaire. Contrary to the outcomes, Gustafsson et al. (2014) evaluated the theories behind the work samples at Swedish schools. The researchers used House to contextualise a transactional philosophy of evaluation. A transactional view means the study focused on different assumptions that made the samples of work at the schools. Hence, a philosophical view from evaluating decisions tries to gather complex data translated as the different views that include the researchers using qualitative data when conducting the evaluation (Gustafsson et al., 2014; House, 1980; Stake, 2005).

\section{Research Questions}

The evaluation aimed for DeLDE to evaluate the ETS Knowledge Model to identify how elearning services support learning and teaching at KAU beyond the pandemic. The following questions guided the evaluation:

1. What data did the ETS Knowledge Model gather for DeLDE at KAU in the second semester of 2019 ?

2. How did the ETS Knowledge Model demonstrate the use of e-learning services like the LMS at KAU in the second semester of 2019?

\section{Methodology}

The literature review revealed the importance of a philosophical evaluation view that acknowledged different perspectives to evaluate the ETS Knowledge Model. It was essential to apply a strategy that recognised the different perspectives. Recognising the different perspectives implied using quantitative and qualitative data for the evaluation. A mixed-method strategy (MMS) (Creswell, 2009; Guba \& Lincoln, 1994) using a case study (Yin \& Davis, 2007) suited the strategy. The methodology section outlines the ETS Knowledge Model followed by the MMS process used to align the two data. After that, the following section provides examples of data used in the ETS Knowledge Model. The section ends with the results.

The ETS Knowledge Model 
The significance of creating new knowledge for DeLDE need not come at a premium because describing the activities may also be supported with explanations about the activities (Ahlström, 2019; Judd, 1987). Thus, knowledge for DeLDE came from evaluating the use of elearning during the crisis. The current study evaluates the ETS Knowledge Model (Figure 3) to understand the knowledge required to sustain e-learning services beyond the pandemic.

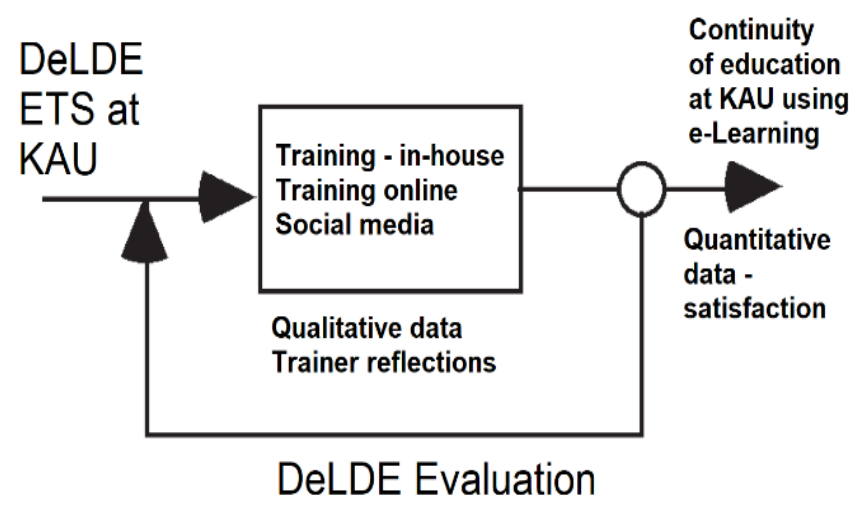

Figure 3. The ETS Knowledge Model

Note. The model describes the ETS Knowledge Model required to sustain education at KAU.

DeLDE maintained a dataset generated from using the ETS Knowledge Model. The dataset from the KAU population generated 4,353 responses - (teachers $n=414$ and students $n=3939$ ). Also, the trainer-teacher documented the reflections of training during the visits to the KAU schools of Medicine, Dentistry, Pharmacy, and Applied Medical Sciences. The reflections were textual and represented the qualitative data. The latitude at KAU (Lebeau \& Alruwaili, 2021) allowed DeLDE to ethically design, use surveys to gather anonymous research data from students and teachers, and host the dataset in a KAU secure online database.

\section{The MMS strategy}

The ETS Knowledge Model needed quantitative data from the students and teachers about their use of the e-learning services. Also, the trainer-researcher reflections were in the form of qualitative data documented during the ETS. The evaluation needed to mix quantitative and qualitative data, which needed a strategy. So, the evaluation took advantage of the MMS. The MMS uses a research scope, historical origins, purpose, timing, weight, and mix relevant for the evaluation (O'Keefe et al., 2020). The scope of the study was restricted to KAU students and teachers who used e-Learning services during the 2019 second semester. Historically, COVID19 derailed education globally. DeLDE prepared a questionnaire and distributed it at the end of the 2019 second semester to all members of KAU using the LMS. The trainer visited the schools to train the teachers at the start of the pandemic in March 2020. Results from the questionnaire and reflections from the trainer were documented.

\section{Sustaining e-learning services through SED}

Teddlie and Tashakkori (2011) suggested a sequential explanatory design (SED). In the SED (Figure 4), the relevant data was collected and analysed in sequential order. First, quantitative data was gathered from the students and teachers who used the e-learning services during the 
pandemic. Once the data was analysed, the next step was to gather qualitative data and analyse it. The SED design provides the evaluation with the results to support answering the research questions.

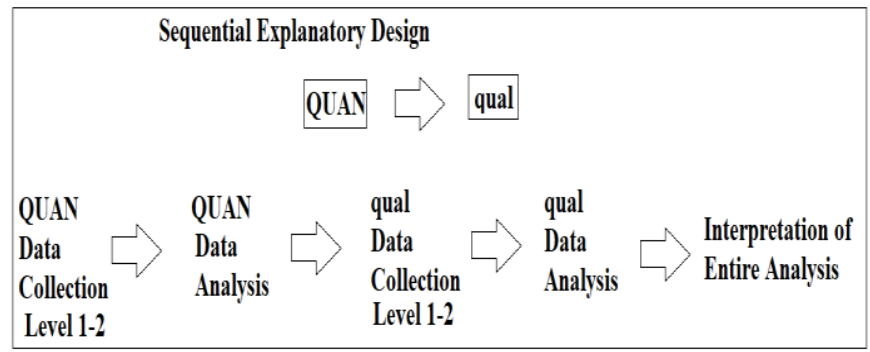

Figure 4 The Mixed method strategy adapted from Creswell (2009).

Incorporating the SED strengthened the evaluation. The incorporation came from the MMS, which recognised the different perspectives and the strength of combining the quantitative and qualitative data in the analysis (Creswell, 2009; Shannon-Baker, 2016). Watson and Watson (2013) indicated the importance of sustainable initiatives through incorporating the MMS. Therefore, DeLDE learned how to sustain its e-Learning services at KAU beyond the pandemic.

\section{Sampling and data gathering procedure}

At the end of the 2019 second semester, DeLDE used a random sampling strategy. DeLDE justified the strategy to gather feedback from all students and teachers about the e-learning services from different members of the colleges at KAU. A banner created in the LMS and KAU emails invited the participants to visit the link housing the online survey. All KAU students $(n=3939)$ and teachers $(n=414)$ were sent separate invitations to complete the survey. The questionnaire used separate items to gather responses from students and teachers.

The responses required the acceptance to give consent and participate in the survey. The items included the demography of the participants, such as their colleges, skill level at using the e-learning service in question, ideas learning and teaching continuity during the pandemic, and suitability of learning and teaching remotely using the LMS. The Faculty of Economics and Administration had the highest response rate from students $(n=707)$, while the English Language Institute had responses from teachers (more than 60).

In terms of items, the survey used a mixture of questions. The questions requested the gender of the students. Also, teachers were asked whether they had attended training during the pandemic before they started teaching online. Finally, other questions requested the participants to agree using a 5-point Likert scale. The demography of the students is shared below, followed by the teachers.

\section{Student background and level of LMS experience}

Three thousand nine hundred thirty-nine students completed the survey, composed of 2,359 female and 1,580 male students came from the student population. The questionnaire grouped some of the responses by gender, such as their opinions about continuing learning online during COVID-19. 
ICT Skills for LMS learning

The students identified their ICT levels as an expert (38.6\%), intermediate $(50 \%)$, and elementary $(11.4 \%)$. Also, $9.2 \%$ of the students reported they had never used the LMS. However, the rest of the students regarded their experience of using the LMS to be either less than a year $(32.5 \%)$, between one and two years $(31.7 \%)$ and more than two years $(26.6 \%)$.

\section{Teacher background and analysis of teacher attitude towards remote teaching}

The distribution of the male and female teachers $(n=414)$ who responded to teachers were even. Most teachers $(n=236)$ were between the 35-50 age group. Two hundred eighty-six of the teachers were qualified at the doctoral level, and more than half of the teachers were professors $(n=58)$, associate professors $(n=72)$, assistant professors participated $(n=142)$. Some teachers were also qualified to masters-level $(n=128)$ and worked as lecturers $(n=107)$.

The teachers identified their ICT skills for teaching on the LMS along with the type of courses. The teachers identified their ICT levels as advanced (58.9\%), intermediate (39.9\%), and a beginner (1.2\%). The teaching experience using the LMS also varied. $37 \%$ of the teachers indicated that they had less than or equal to one year's experience. $23.2 \%$ indicated that they had between one-and-two years' experience. $39.9 \%$ of the teachers had more than two years of experience. Finally, the survey also revealed that a large majority of the teachers $(74.2 \%)$ had attended LMS training to prepare them for teaching online during the pandemic.

\section{Results and Analysis}

The results section begins with the students' responses. The responses from the students are presented, followed by the teachers. The responses displayed the results using the frequency table to demonstrate the type of data the ETS Knowledge Model captured. First, the students' opinions are presented, followed by the teachers' opinions.

\section{Student attitudes}

The students $(n=3939)$ provided their opinion on the continuity of learning online. Also, the students respond to continuity of studying online after the pandemic.

\section{Continuity of learning online}

The data shows (Figure 5) that male and female students agreed that their education continued during COVID-19.

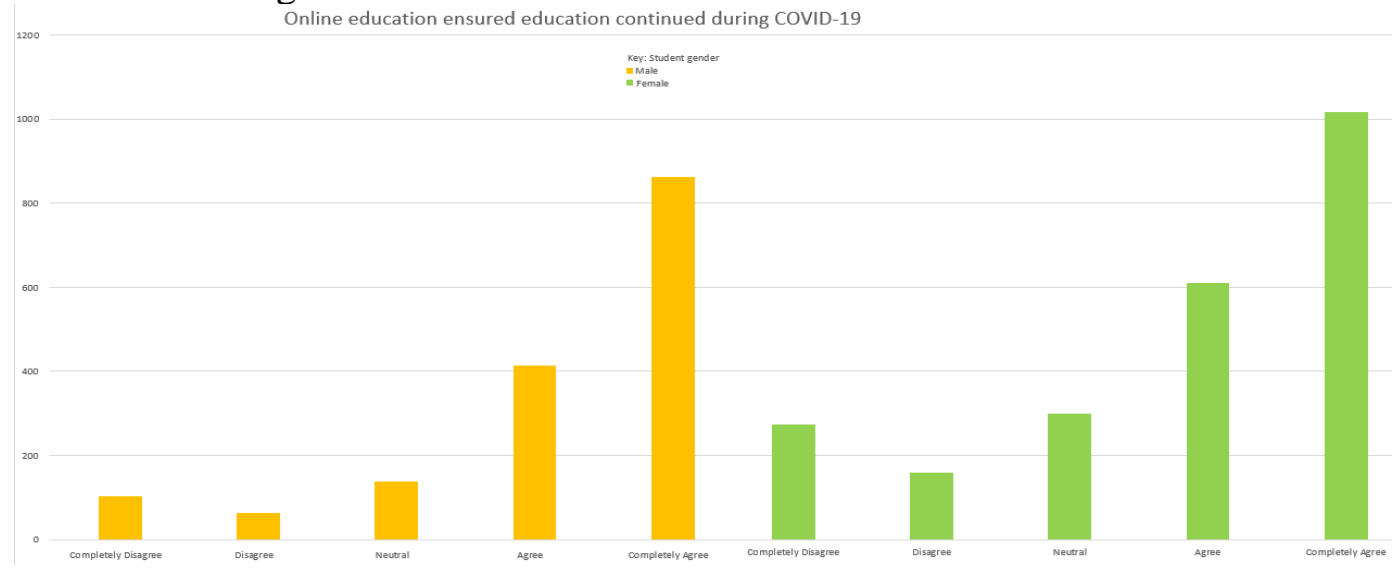

Figure 5 Opinion about online education during COVID-19 
The male $(\mathrm{n}=1627)$ and female $(\mathrm{n}=1276)$ students agreed that online education ensured education continued during the COVID-19. The male students showed more disagreement $(\mathrm{n}=432)$, and 300 students remained neutral. The female students indicated their disagreement $(\mathrm{n}=167)$, with 137 students remained neutral.

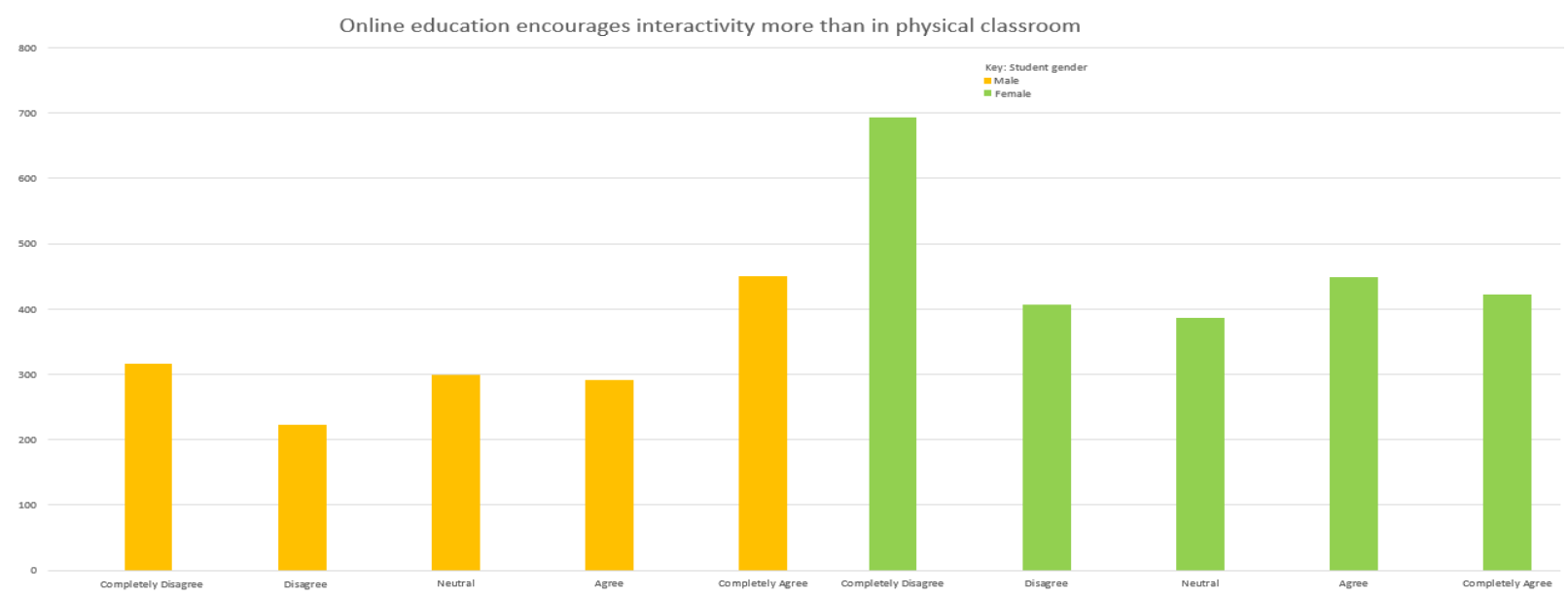

Figure 6 Online education and interaction

The students indicated that they agreed that online education encouraged interaction. However, the female students $(n=1107)$ disagreed more than the male students $(n=540)$. The male students indicated their agreement $(\mathrm{n}=741)$, and 299 students remained neutral. Also, the female students indicated their agreement $(\mathrm{n}=871)$, with 387 students remained neutral.

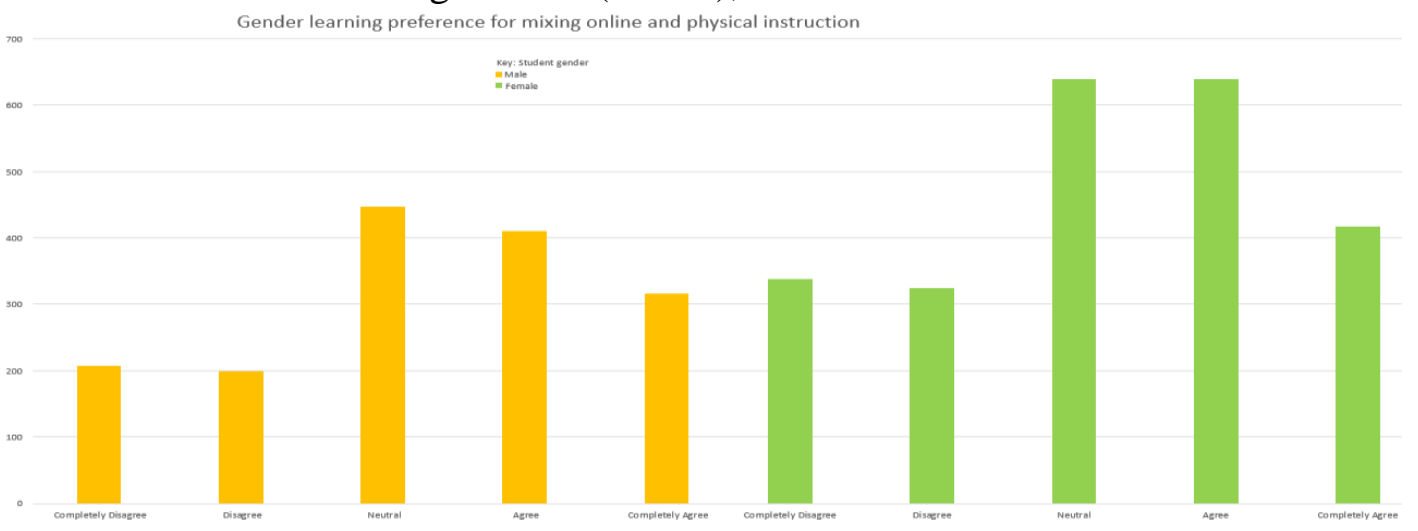

Figure 7 Preference for mixing instruction online and in the classroom

The students indicated they agreed with blending instruction, defined as mixing instruction online and in the physical classroom. However, the female students $(n=1627)$ were more in agreement than the male students $(\mathrm{n}=1276)$. The male students indicated their disagreement $(\mathrm{n}=167)$, and 137 students remained neutral. Also, the female students indicated their disagreement $(n=432)$, with 300 students remained neutral.

Teacher attitudes

Similarly, the results for the teachers displayed their responses. The teachers provided their opinions about teaching online using the LMS, training to teach online, and mixing instruction online and in the physical classroom. 
LMS teaching experience and continuity of education

The teachers $(\mathrm{n}=414)$ were grouped according to their LMS teaching experience. So, the teachers who had 0-1 LMS experience $(\mathrm{n}=129)$, between 1-2 LMS experience $(\mathrm{n}=85)$, and more than two years' ( $\mathrm{n}=146)$ LMS experience indicated agreement that teaching online ensured the continuity of education during COVID-19.

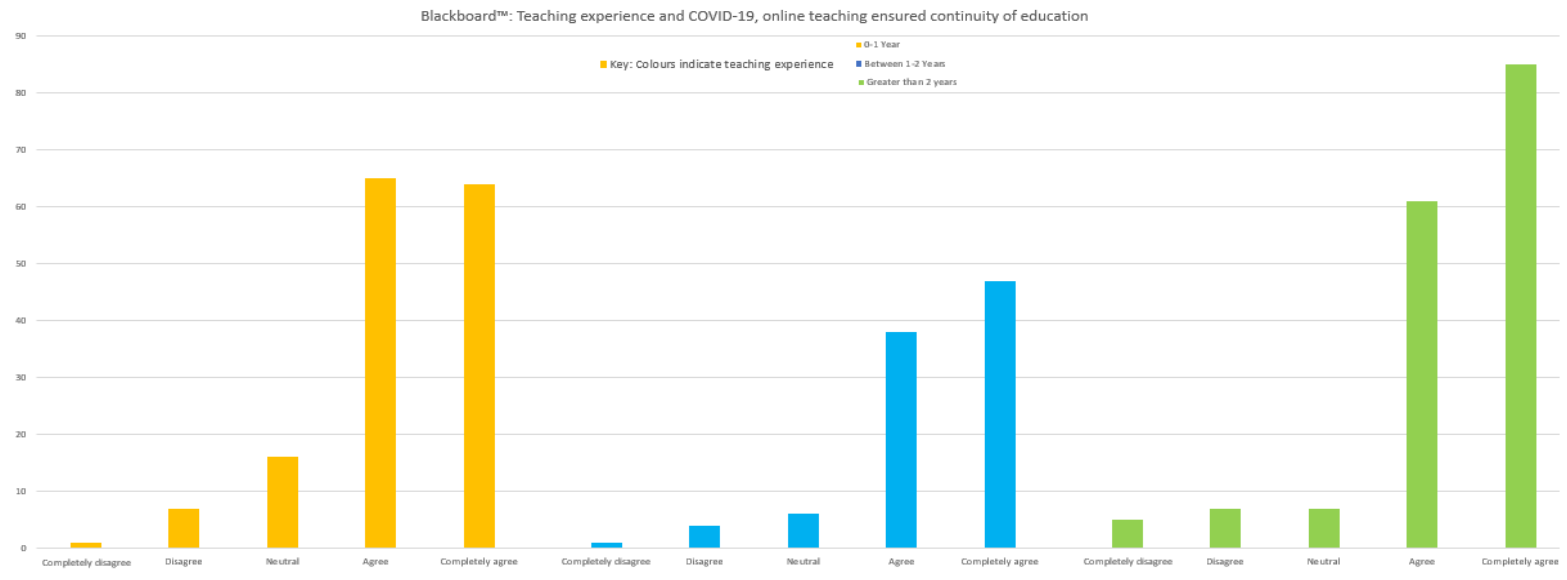

Figure 8 COVID-19 and LMS experience about the continuation of education

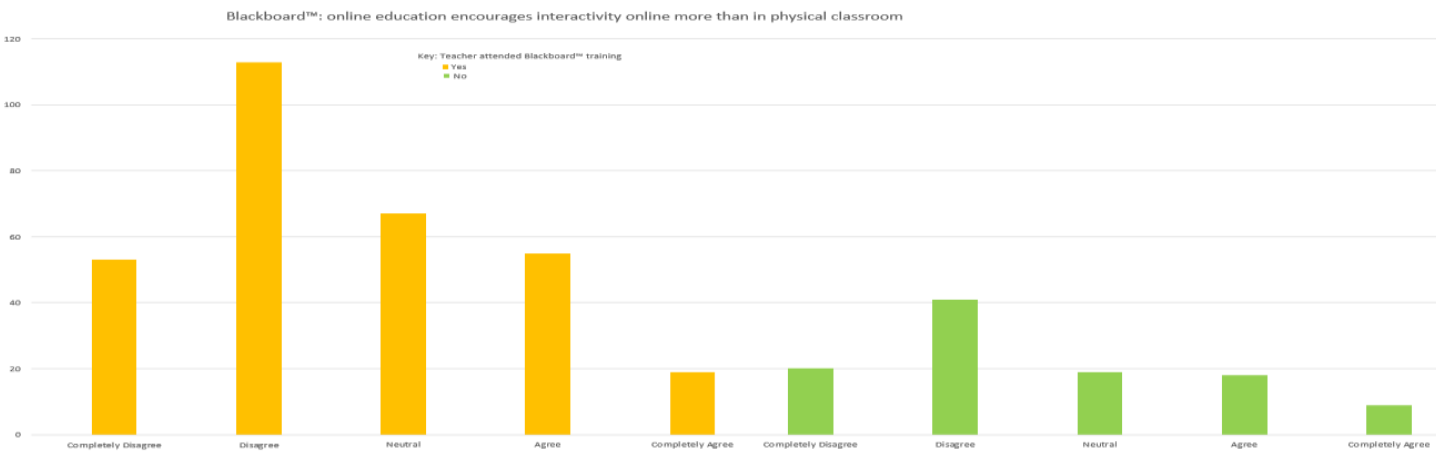

Figure 9 LMS training and the encouragement of interactivity online and in a physical classroom

The teachers who had taken the LMS training $(\mathrm{n}=141)$ during COVID-19 indicated a higher disagreement $(n=166)$ for interactivity in the LMS than teachers $(n=61)$ who had not taken training $(\mathrm{n}=107)$.

\section{Analysis of quantitative data}

The results from the survey indicated that DeLDE used the ETS Knowledge Model to capture the feedback from students and teachers. The frequency tables to analyse the data were sufficient to evidence that DeLDE had gathered data from students and teachers regarding the continuation of education and training during the peak of the pandemic at KAU. The survey questionnaire was sent towards the end of the second semester in 2019. Gathering feedback from the students and teachers represented gathering reactions at the end of a period. Researchers who evaluated programmes have gathered quantitative data from students and teachers at the end of the programme (Alsalamah \& Callinan, 2021; Asgar \& Satyanarayana, 2021; Patel et al., 2018). The researchers also used the Kirkpatrick Model (1998) to evaluate the outcome of the 
programmes. Evaluating the programme's outcome represented a philosophical view of evaluation (Easterby-Smith, 1994) which uses quantitative data. Likewise, the Kirkpatrick Model uses quantitative data to generate a Level 1 analysis of the programme from participants. Finally, a quantitative view of evaluation also included a behaviourist perspective towards learning (Hean et al., 2009). Critically, the evidence supports answering the first research question about the ETS Knowledge Model based on the first sequence (Creswell, 2009; Shannon-Baker, 2016) to suggest that DeLDE had gathered quantifiable evidence from 3,939 students and 414 teachers at KAU. The following section begins the qualitative data sequence.

\section{Contextualising critical reflection as evaluation}

The qualitative data sequence uses the reflections from the trainer-researcher. It is common for evaluation to include prior knowledge as part of the data (Cohen et al., 2006; Durand et al., 2014; Hean et al., 2009; Mulcahy, 2020; Siengthai, 2015). In the current research, the view of prior knowledge is contextualised as critical reflection (2009; Mezirow, 1990), which puts a constructivist philosophy of learning into evaluating the ETS Knowledge Model. The philosophy places the standard by which to analyse the results of the data.

The critical reflection used in the evaluation required two steps. First, the trainer-researcher uncovered any significant learning from training the participants at the KAU schools of Medicine, Dentistry, Pharmacy and Applied Medical Sciences in the second semester of 2019. Second, the trainer-researcher shared the critical reflection for critique. The experience resulted in documenting the experience and partly sharing the reflection online (E4ENG, 2020; Joinson, 2012) after visiting the Schools of Medicine, Dentistry, Pharmacy, and Applied Medical Sciences. At the time, the trainer did not consider using the document for research. The custom of the trainer was to journal his communication and thoughts online. The online reflections did not identify the trainees or put any of them at risk. Before gaining access to the research, the proposal included ethical clearance from the KAU Research Deanship (Coffey, 2014). Hence, the documentary evidence from the critical reflection provides insight for evaluating the ETS Knowledge Model (Hean et al., 2009; McIntosh et al., 2018; Mezirow, 1990; Mulcahy, 2020; Osam \& Nold, 2020; Siengthai, 2015).

\section{Analysis of reflection from training in-house}

The documented data from the trainer-researcher provided reflections about what was taking place during the on-site training sessions (Webb et al., 2000). The trainer's concern in the reflections was related to the circumstances for training - one concern related to future sessions in a post-coronavirus environment. The trainer answered many questions by interacting with the teachers during the training sessions. The interactions became the entry point for the trainer's reflections. Critical reflection requires the interaction between the trainer and trainees. In the trainees' questions, the trainer ascertained how the trainees understood and were ready to support their students using the e-learning services. It was possible to distinguish how similar or different the participants were using Becker and Geer (1960) to analyse the critical reflection. The trainer partly shared the reflections online (E4ENG, 2020; Joinson, 2012). The reflections contained non-confidential information nor disclosed any identities of the trainees online. 


\section{Reflection on the LMS training}

The trainees were given some training on how to log and access the LMS. During the session, the trainer-researcher observed the trainees, then, after the training session, documented the observations (Cohen et al., 2006; Durand et al., 2014). Coffey (2014) defined the documented reflections as providing real-life examples for DeLDE during the pandemic. A reallife example of life during the pandemic was a helpful way to capture the teachers' profound realities (Becker \& Geer, 1960). The reflections were also representative of life during the pandemic because it was written outside the research. During the sessions (Figure 11), the trainer noticed that the teachers asked questions according to their abilities to use the LMS or help their students.

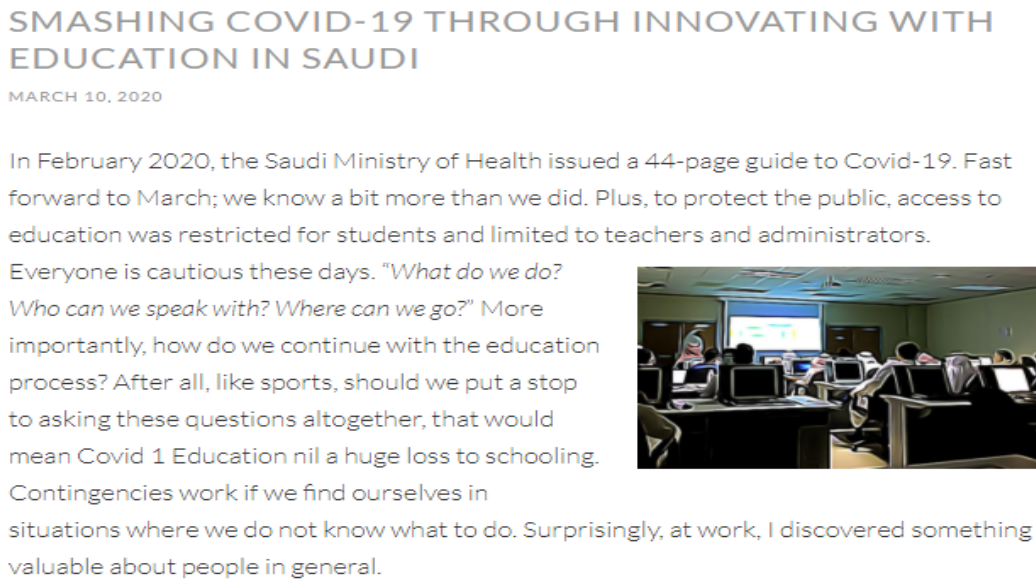

Figure 10 The trainer reflection during the COVID-19 emergency training session

Note. Observation from trainer shared online at E4ENG (2020)

New-navigators and functional users

The reflections from the trainer referred to the use of online learning during the training sessions. The training sessions provided an avenue where the trainer-researcher interacted with the trainees. It was part of critical reflection to have the interaction occur. Then the trainerresearcher generated the reflection as meaningful (Mezirow, 1990).

\section{New-navigators}

On the one hand, the trainer observed that some users were entering the online world for teaching purposes for the first time. The new-navigators made comments such as the following:

How can I log in?

How can I change the language? [Arabic to English or vice versa]

Where did the folder go to? [After creating a folder in the LMS]

Sample new-navigator comments

The teachers new in the LMS world fell into the new-navigator category. The new navigators needed some information about how to navigate the system. Thus, their concerns were technical and operational use rather than the educational value of the LMS. 
Arab World English Journal (AWEJ) 2nd Special Issue on Covid 19 Challenges January 2022

The King Abdulaziz University COVID-19 e-vaccine: An Evaluation

Bardesi \& Garba

\section{Functional users}

On the other hand, the trainer-researcher observed that teachers with some experience in using the LMS asked practical questions about how to help their students.

The functional users made comments such as the following:

How can I view my students' grades?

I have quizzes online, how can I download the results?

Can we use different types of assessments online?

Sample functional user comments

The practical questions that the functional users asked were often related to specific functions of the LMS to provide something meaningful to their students. The experienced teachers fell into the functional users of the LMS. The functional users needed to help their students to complete tasks in the LMS.

The distinction between navigator and functional users came out of analysing the reflections during the training sessions at the different KAU Schools (Bonk, 2016; Hean et al., 2009). The trainer-researcher responding to the questions from the functional users and new-navigators represented the interaction between users and the trainer-researcher. However, at the time of recording the reflections, researching was further from the trainer's mind. Hence, the reflections documented provided real-world examples of what went into training during the pandemic. The documenting of the reflections at that time provided a valid use of the reflections (EasterbySmith, 1994). Thus, the trainer-researcher identified new-navigator, and functional were valid evidence based on the critical reflections for DeLDE to evaluate the e-learning service.

\section{Analysis of the critical reflection}

The new-navigators and functional users were presented as from the critical reflection of the trainer-researcher. Analysing the emerging users followed the pattern of using the SED in the current MMS evaluation. Also, Flanagan (1949) included the new-navigators and functional users as critical to using the e-learning services beyond the pandemic (Cohen et al., 2006; Durand et al., 2014). Hence, the critical reflection captured qualitative data for the ETS Knowledge Model. The results of the qualitative data showed that the ETS Knowledge Model included the critical reflections from the trainer-researcher. Also, critical reflection emanated from a constructivist philosophy of evaluation. Constructivism recognised contexts crucial for understanding how to sustain e-learning services in a post-pandemic world. The contexts brought the process, leading the trainer-researcher to categorise the trainees as new-navigator and functional users. Therefore, the critical reflection added some complexity by using data from the trainer-researcher. The data captured the interactions and reflections from the training activities at the different KAU schools (Gustafsson et al., 2014; House, 1980; Stake, 2005).

\section{The e-vaccine: Combined interpretation of the analysis}

The evaluation took advantage of the quantitative and qualitative data analysis. The advantage provided evidence for the second research question. The significance of the evidence showed how the ETS Knowledge Model demonstrated the use of the LMS from two points. The first point uses the student and teacher opinions from the survey. The second point uses the findings from the critical reflection. The quantitative data used the students' reactions. The evidence indicated that under the COVID-19 conditions, female $(n=2359)$ and male $(n=1580)$ 
students agreed that their learning continued online in the LMS in the second semester of 2019. Also, teachers $(n=414)$ at KAU from different ranks taught different courses on the LMS. The reactions indicated an agreement that learning and teaching continued during the pandemic. One key reason was that the reactions came from the students and teachers about the continuity of learning and teaching, training and use of the LMS at KAU. The reactions were contextualised within a Kirkpatrick model to be at Level 1 and 2 feedback.

A behaviourist perspective gave the reaction an outcome of using the e-learning services (Hean et al., 2009). Thus, the use of the LMS can be demonstrated through the behaviourist view. The view showed the quantitative data as evidence for the use of the LMS in the second semester of 2019. The current evaluation agrees with other studies that used quantitative data (Asgar \& Satyanarayana, 2021; Siengthai, 2015; Sim \& Radloff, 2008). Also, O'Keefe et al. (2020) conducted a study within the same Saudi context with findings relevant for the current evaluation. O'Keefe et al. (2020) found students to agree that their teachers communicated with them during the pandemic. Also, the teachers and their administrators are expected to communicate online with students. AI-Youbi et al. (2020) also confirmed the use of social media as one of the important chains within the link between the KAU community members during the pandemic. The results from different researchers about the students, teachers demonstrated that the using the quantitative data in the evaluation provided the ETS Knowledge Model relevant data for DeLDE. The data gathered indicates the continuity of education at KAU. Finally, the ETS Knowledge Model has evidence to support the student and teacher usages of e-learning services provided by DeLDE during the pandemic. One reason for the evidence came from the evaluation taking different perspectives to ensure that the value of the evaluation benefited DeLDE to improve its e-learning services.

In the context of the qualitative data, the trainer-researcher offered critical reflections from observing the participants trained at the KAU Schools of Medicine, Dentistry, Pharmacy, and Applied Medical Sciences. The critical reflection produced new-navigators and functional users. The critical reflection offered context for gauging the process by making consideration of the roles of the users. Users of the e-learning services such as the LMS can adopt different roles. So, a trainee could progress beyond the new-navigator and adopt a functional user role. DeLDE needs to capture what might cause the changing roles. Bonk (2016) contextualises the disruption that has caused teachers to change their roles. The previous traditional rule-following role needed to accommodate knowledge curators. Hence, the new-navigator concerned with manipulating the LMS will emerge with concerns for students in a functional user role. Bonk (2016) and Bonk et al. (1994) offer roles beyond the ones identified in the critical reflection to suggest that the roles significantly impact education. The considerations of how the roles change require DeLDE to document and emphasise the process that leads changes to occur during the training and between trainer and trainee. So, using the process and documenting the work, DeLDE can record what the trainers use to improve the teaching and learning process. Also, the teachers could indicate what happens when they use the measures within their disciplines to maintain a continuous link between DeLDE and the programs (Easterby-Smith, 1994; Holmes \& Gardner, 2006; Lave \& Wenger, 1991). The critical reflection demonstrates that the ETS Knowledge Model extended the training to include the documentation process of changes during the training sessions. 
The goal for DeLDE to support its wider KAU community (Alsowayegh et al., 2018) came from a combination of perspectives that demonstrate how DeLDE supports the community at KAU to use the e-learning services for teaching and learning during COVID-19 in the second semester of 2019 (Rosellini, 2019). Also, the decision from the Dean's office to utilise the ETS Knowledge Model has gathered evidence from students, teachers, and the trainer reflections to indicate the sustainment of education during the COVID-19 pandemic at KAU (AI-Youbi et al., 2020). Finally, the evaluation has gone beyond the continuity of education to make two suggestions. The first suggestion encourages training initiatives that integrate reflections from learning and teaching when using the e-services DeLDE provides the KAU community. The second suggestion integrates standards that encourage DeLDE to remain consistent in providing training for its e-learning services steeped in pedagogy in the post-pandemic period. Some valuable measures impact the suggestions (Rosellini, 2019). First, reflection gives the means to measure the process involved when generating knowledge that involves the KAU community to engage with DeLDE strategic goals when training. Second, standards give the means to measure the knowledge generated from the community concerning DeLDE goals to support learning and teaching at KAU. Thus, DeLDE can improve the creation of knowledge measurably to encourage reflective practice, which utilises teachers and trainers' shared work that use the elearning services provided for teaching at KAU.

\section{Conclusion}

The evaluation aimed to evaluate the ETS Knowledge Model by adopting different perspectives into the evaluation. So, it was necessary to take advantage of the MMS in a case study. The ETS Knowledge Model gathered quantitative data and qualitative data for DeLDE to evaluate how e-learning services supported learning and teaching at KAU beyond the pandemic at KAU in the second semester of 2019. The quantitative data showed that the male $(n=1627)$ and female $(\mathrm{n}=1276)$ students agreed that online education continued during COVID-19. As for the teachers $(n=414)$ based on their teaching experience in the LMS, those who had $0-1(n=129)$, between 1-2 $(n=85)$, and more than two years' $(n=146)$ LMS experience indicated agreement that teaching online ensured the continuity of education during COVID-19. Finally, the teachers who had taken the LMS training $(n=141)$ during COVID-19 indicated a higher disagreement $(n=166)$ for interactivity in the LMS than teachers $(n=61)$ who had not taken training $(n=107)$. Gathering feedback from the students and teachers represented gathering reactions at the end of a period. Researchers who evaluated programmes have gathered quantitative data from students and teachers at the end of the programme (Alsalamah \& Callinan, 2021; Asgar \& Satyanarayana, 2021). Critically, the quantitative evidence supports the first and second research questions about the ETS Knowledge Model. Based on the first phase of the SED, DeLDE had gathered quantifiable evidence from 3,939 students and 414 teachers at KAU. Also, the quantitative view of evaluation included a behaviourist perspective. The perspective demonstrates how the ETS Knowledge Model used the behaviourist perspective to gather the data. A constructivist perspective links the ETS Knowledge Model with evaluators that recognised prior knowledge when evaluating the ETS process. It was also crucial for DeLDE to utilise critical reflection concerning achieving DeLDE goals, which placed a philosophical view of evaluating the goals and decisions that supported the Knowledge Model (Gustafsson et al., 2014; House, 1980; Stake, 2005). 
The current evaluation of the ETS Knowledge Model represents the complex view of evaluation that considers the value of evaluation from learning theories and a philosophical view of evaluation. That complexity has a limiting impact and a positive one on the evaluation. First, the limitation on the evaluation comes from combining the perspectives and data, which consumes time. Second, the positive impact on the evaluation involves using the complexity to produce the research, the first of its kind from the context of DeLDE operating from KAU. Finally, as the global COVID-19 research gathers momentum, our evaluation promotes the engagement of different perspectives when evaluating learning and teaching at higher education institutions.

We offer critical insight from the review of the literature and the results of the evaluation. First, the evaluation outlines the importance of evaluators bringing some assumptions with them when evaluating programmes. In the case of DeLDE, the assumptions promoted the interest of DeLDE in generating knowledge from different perspectives regarding DeLDE's e-learning services contextualised as the ETS Knowledge Model. The assumptions gave importance to behaviourist and constructivist learning theories and a goal and decision-making philosophy of evaluation. Finally, contextualising the participant-researchers as the Dean and trainer at DeLDE, the evaluation gained from the participants' familiarity of the ETS Knowledge Model's context.

An added significance for the conclusion was the strategic advantage the research offers using the insight from the review. The advantage includes using students, teachers, and trainers' data to understand the issues of learning and teaching during the critical period of the pandemic. Also, from the data, we understand how DeLDE supported learning and teaching during the period.

Finally, our evaluation promotes KAU by actively supporting DeLDE activities that encourage e-learning services for learning and teaching to sustain development in the region (Alsowayegh et al., 2018; AI-Youbi et al., 2020; O'Keefe et al., 2020; Valderrama-Hernández et al., 2020).

\section{Acknowledgement}

This research work was funded by Institutional Fund Projects under Grant No (IFPAS-075214-2020). Therefore, the authors gratefully acknowledge technical and financial support from the Ministry of Education and King Abdulaziz University, Jeddah, Saudi Arabia.

\section{About the authors}

Dr. Hisham J Bardesi is the Dean of Deanship e- Learning and Distance Education at King Abdulaziz University (KAU), Jeddah, Saudi Arabia. He promotes e-learning in higher education. ORCID: http://orcid.org/0000-0003-3137-0429

Ibrahim Garba is the e-learning coordinator, consultant, English language Lecturer and teacher trainer at King Abdulaziz University. He has interest in educational technology and country development through education. His research includes communicating policy research to inform policy and strategic development. ORCID: http://orcid.org/0000-0002-6395-697X 
Arab World English Journal (AWEJ) 2nd Special Issue on Covid 19 Challenges January 2022

\section{References}

Ahlström, H. (2019). Policy hotspots for sustainability: Changes in the EU regulation of sustainable business and finance. Sustainability (Switzerland), 11(2). https://doi.org/10.3390/su11020499

AI-Youbi, A. O., Al-Hayani, A., Bardesi, H. J., Basheri, M., Lytras, M. D., \& Aljohani, N. R. (2020). The King Abdulaziz University (KAU) pandemic framework: A methodological approach to leverage social media for the sustainable management of higher education in crisis. Sustainability, 12(11), 4367. https://doi.org/10.3390/su12114367

Almaiah, M. A., \& Alyoussef, I. Y. (2019). Analysis of the effect of course design, course content support, course assessment and instructor characteristics on the actual use of Elearning system. IEEE Access, 7, 171907-171922. https://doi.org/10.1109/ACCESS.2019.2956349

Alsalamah, A., \& Callinan, C. (2021). Adaptation of Kirkpatrick's four-level model of training criteria to evaluate training programmes for head teachers. Education Sciences, 11(3), 116. https://doi.org/10.3390/educsci11030116

Alsowayegh, N., Baradesi, H., \& Garba, I. (2018). Creating an effective e-learning content: implications for a language learning program. 12th Annual International Technology, Education and Development Conference, 1, 8603-8611. https://doi.org/10.21125/inted.2018.2086

Asgar, A., \& Satyanarayana, R. (2021). An evaluation of faculty development programme on the design and development of self-learning materials for open distance learning. Asian Association of Open Universities Journal, 16(1), 98-115. https://doi.org/10.1108/aaouj-112020-0094

Ballantine, J., Levy, M., Martin, A., Munro, I., \& Powell, P. (2000). An ethical perspective on information systems evaluation. International Journal of Agile Management Systems, 2(3), 233-241. https://doi.org/10.1108/14654650010356149

Barnes, S. J. (2020). Information management research and practice in the post-COVID-19 world. International Journal of Information Management, 55. https://doi.org/10.1016/j.ijinfomgt.2020.102175

Becker, H., \& Geer, B. (1960). Participant observation: The analysis of qualitative field data. In R.Adams \& J.Preiss (Eds.), Human Organization Research: Field Relations and Techniques.

Bonk, C. J. (2016). Keynote: What is the state of e-learning? Reflections on 30 ways learning is changing. Journal of Open, Flexible and Distance Learning, 20(2), 6-20. https://www.academia.edu/30032706/Bonk_C._J._2016_._What_is_the_state_of_elearning_Reflections_on_30_ways_learning_is_changing._Journal_of_Open_Flexible_and_ Distance_Learning_20_2_6-20?auto=download

Bonk, C. J., Medury, P. V., \& Reynolds, T. H. (1994). Cooperative hypermedia: The marriage of collaborative writing and mediated environments. Computers in the Schools, 10(1-2), 79124. https://doi.org/10.1300/J025v10n01_08

Brinkerhoff, R. O. (2005). The success case method: A strategic evaluation approach to increasing the value and effect of training. Advances in Developing Human Resources, 7(1), 86-101. https://doi.org/10.1177/1523422304272172

Burke, L. A., \& Hutchins, H. M. (2007). Training transfer: An integrative literature review. Human Resource Development Review, 6(3), 263-296. https://doi.org/10.1177/1534484307303035 
Arab World English Journal (AWEJ) 2nd Special Issue on Covid 19 Challenges January 2022

Cameron, K. S., \& Whetten, D. A. (1983). Some conclusions about organizational effectiveness. In Organizational Effectiveness (pp. 261-277). https://doi.org/10.1016/b978-0-12-157180$1.50017-3$

Coffey, A. (2014). Analysing documents. In U. Flick (Ed.), The SAGE Handbook of Qualitative Data Analysis (pp. 367-379). https://doi.org/10.4135/9781446282243.n25

Cohen, D. J., Leviton, L. C., Isaacson, N., Tallia, A. F., \& Crabtree, B. F. (2006). Online diaries for qualitative evaluation: Gaining real-time insights. American Journal of Evaluation, 27(2), 163-184. https://doi.org/10.1177/1098214006288448

Creswell, J. W. (2009). Mixed methods procedures. In Research design: Qualitative, quantitative and mixed methods approaches (3rd ed., pp. 203-226). Sage.

Durand, R., Decker, P. J., \& Kirkman, D. M. (2014). Evaluation methodologies for estimating the likelihood of program implementation failure. American Journal of Evaluation, 35(3), 404-418. https://doi.org/10.1177/1098214014523824

E4ENG. (2020). Smashing COVID-19 through innovating with education in Saudi. E4ENG Blog. https://e4eng.wordpress.com/2020/03/10/smashing-covid-19-innovating-education-insaudi/

Easterby-Smith, M. (1994). Evaluating, management development, training and education. Gower.

Flanagan, J. (1949). Critical requirements: A new approach to employee evaluation. In E. C. Wragg (Ed.), An Introduction to Classroom Observation. Routledge.

Galloway, D. L. (2005). Evaluating distance delivery and e-learning is kirkpatrick's model relevant? Performance Improvement, 44(4), 21-27. https://doi.org/10.1002/pfi.4140440407

Guba, E. G., \& Lincoln, Y. S. (1994). Competing paradigms in qualitative research. In N. K. Denzin \& Y. S. Lincoln (Eds.), Handbook of qualitative research (pp. 105-117). Sage.

Gustafsson, J.-E., Lander, R., \& Myrberg, E. (2014). Inspections of Swedish schools: A critical reflection on intended effects, causal mechanisms and methods. Education Inquiry, 5(4), 461-479.

Hean, S., Craddock, D., \& O'Halloran, C. (2009). Learning theories and interprofessional education: A user's guide. Learning in Health and Social Care, 8(4), 250-262. https://doi.org/10.1111/j.1473-6861.2009.00227.x

Holmes, B., \& Gardner, J. (2006). e-Learning: Concepts and practice. In e-Learning: Concepts and Practice. SAGE Publications Ltd. https://doi.org/10.4135/9781446212585

House, E. R. (1980). Evaluating with validity. Sage.

Ilhan, A. (2020). Organizational Goals: A theoretical examination on classification. International Journal of Management (IJM), 11(7), 1086-1098. https://doi.org/10.34218/IJM.11.7.2020.096

Joinson, A. N. (2012). Gathering data on the Internet: Qualitative approaches and possibilities for mixed methods research. In A. Joinson, K. McKenna, U. Reips, \& T. Postmes (Eds.), Oxford Handbook of Internet Psychology (pp. 405-428). Oxford University Press. https://doi.org/10.1093/oxfordhb/9780199561803.013.0026

Judd, C. M. (1987). Combining process and outcome evaluation. In New Directions for Program Evaluation (Vol. 1987, Issue 35, pp. 23-41). https://doi.org/10.1002/ev.1457

Kirkpatrick, D. L. (1998). Evaluating training program. Berrett Koehler Publishers.

Kirkpatrick, D. L., \& Kirkpatrick, J. D. (2009). Evaluating: Part of a ten-step process. In Evaluating Training Programs (pp. 3-20). Berrett-Koehler Publishers.

Lave, J., \& Wenger, E. (1991). Situated learning: Legitimate peripheral participation. 
Arab World English Journal (AWEJ) 2nd Special Issue on Covid 19 Challenges January 2022

Cambridge University Press.

Lebeau, Y., \& Alruwaili, J. (2021). Convergence and local orders in the dynamics of change in higher education: A perspective from Saudi Arabia. Policy Reviews in Higher Education, 121. https://doi.org/10.1080/23322969.2021.1904791

Lee, C., Jeon, D., Kim, W., \& Lee, J. (2017). Evaluating training for new government officials: A case study using the Success case method. Public Personnel Management, 46(4), 419444. https://doi.org/10.1177/0091026017730382

Marshall, S. J. (2018). Shaping the university of the future: Using technology to catalyse change in university learning and teaching. In Shaping the University of the Future: Using Technology to Catalyse Change in University Learning and Teaching. Springer Singapore. https://doi.org/10.1007/978-981-10-7620-6

McIntosh, T., Higgs, C., Mumford, M., Connelly, S., \& DuBois, J. (2018). Continuous evaluation in ethics education: A case study. Science and Engineering Ethics, 24(2), 727754. https://doi.org/10.1007/s11948-017-9927-x

Mezirow, J. (1990). How critical reflection triggers transformative learning. In Fostering critical reflection in adulthood: A guide to transformative and emancipatory learning (p. 12).

Mulcahy, R. S. (2020). Creating effective elearning to help drive change. Journal of Chemical Health and Safety, 27(6), 362-368. https://doi.org/10.1021/acs.chas.0c00091

O'Keefe, L., Dellinger, J. T., Mathes, J., Holland, T. L., \& Knott, J. (2020). The state of online learning in the Kingdom of Saudi Arabia: A COVID-19 impact study for higher education.

Osam, E. K., \& Nold, K. (2020). A case study on the application of a human performance technology model to a sports product manufacturing company. Performance Improvement, 59(5), 17-25. https://doi.org/10.1002/pfi.21916

Patel, S. R., Margolies, P. J., Covell, N. H., Lipscomb, C., \& Dixon, L. B. (2018). Using instructional design, analyze, design, develop, implement, and evaluate, to develop eLearning modules to disseminate supported employment for community behavioral health treatment programs in New York State. Frontiers in Public Health, 6. https://doi.org/10.3389/fpubh.2018.00113

Reio, T. G., Rocco, T. S., Smith, D. H., \& Chang, E. (2017). A critique of Kirkpatrick's evaluation model. New Horizons in Adult Education and Human Resource Development, 29(2), 35-53. https://doi.org/10.1002/nha3.20178

Rosellini, A. (2019). Effective knowledge transfer and behavioural change in a training environment. Journal of Information \& Knowledge Management, 18(04), 1950049. https://doi.org/10.1142/S0219649219500497

Shannon-Baker, P. (2016). Making paradigms meaningful in mixed methods research. Journal of Mixed Methods Research, 10(4), 319-334. https://doi.org/10.1177/1558689815575861

Siengthai, S. (2015). A reflection on a leadership training programme of the ministry of interior, Thailand. Human Resource Development International, 18(3), 317-324. https://doi.org/10.1080/13678868.2015.1071992

Sim, J., \& Radloff, A. (2008). Enhancing reflective practice through online learning: Impact on clinical practice. Biomedical Imaging and Intervention Journal, 4(1). https://doi.org/10.2349/biij.4.1.e8

Stake, R. E. (2005). Qualitative case studies. In N. K. Denzin \& Y. S. Lincoln (Eds.), The SAGE handbook of qualitative research (3rd ed., pp. 443-466). Sage Publications.

Teddlie, C., \& Tashakkori, A. (2011). Mixed methods research: Contemporary issues in an emerging field. In N. K. Denzin \& Y. S. Lincoln (Eds.), The SAGE handbook of qualitative 
research (pp. 285-299). Sage.

UNESCO. (2020). COVID-19 Educational disruption and response. COVID-19. https://en.unesco.org/covid19/educationresponse

Valderrama-Hernández, R., Sánchez-Carracedo, F., Rubio, L. A., \& Limón-Domínguez, D. (2020). Methodology to analyze the effectiveness of ESD in a higher degree in education. A case study. Sustainability (Switzerland), 12(1), 1-27. https://doi.org/10.3390/SU12010222

Venkatraman, N., \& Ramanujam, V. (1986). Measurement of business performance in strategy research: A comparison of approaches. Academy of Management Review, 11(4), 801-814. https://doi.org/10.3402/edui.v5.23862

Watson, W. R., \& Watson, S. L. (2013). Exploding the ivory tower: Systemic change for higher education. TechTrends, 57(5), 42-46. https://doi.org/10.1007/s11528-013-0690-9

Webb, E. J., Campbell, D. T., Schwartz, R. D., \& Sechrest, L. (2000). Unobtrusive measures: Nonreactive research in the social sciences. In Journal of the American Statistical Association (Vol. 65, Issue 331). Sage Publications.

Weick, K. E. (1976). Educational organizations as loosely coupled systems. Administrative Science Quarterly, 21, 1-19.

Yin, R. K., \& Davis, D. (2007). Adding new dimensions to case study evaluations: The case of evaluating comprehensive reforms. New Directions for Evaluation, 2007(113), 75-93. https://doi.org/10.1002/ev.216 